\title{
The Tropical Atmosphere Ocean Array Is Completed
}

\author{
Michael J. McPhaden \\ NOAA/Pacific Marine Environmental Laboratory, Seattle, Washington
}

Implementation of the Tropical Atmosphere Ocean (TAO) array of moored buoys in the Pacific Ocean was completed on 17 December 1994 with deployment of the 69th and final mooring at $8^{\circ} \mathrm{N}, 156^{\circ} \mathrm{E}$ from the Taiwanese research vessel Ocean Research I. The TAO array measures oceanographic and surface meteorological variables critical for improved detection, understanding, and prediction of seasonal to interannual climate variations originating in the Tropics, most notably those related to the EI Niño/Southern Oscillation (ENSO). The array spans one-third the circumference of the globe, from $95^{\circ} \mathrm{W}$ near the Galápagos Islands to $137^{\circ} \mathrm{E}$ off the coast of New Guinea (Fig. 1). Moorings are deployed every $2^{\circ}-3^{\circ}$ of latitude between $8^{\circ} \mathrm{N}$ and $8^{\circ} \mathrm{S}$ along lines that are separated by $10^{\circ}-15^{\circ}$ of longitude. Data are reported in real time via Service Argos, which uses National Oceanic and Atmospheric Administration (NOAA) polar-orbiting weather satellites for data relay. TAO data are then retransmitted on the Global Telecommunication System for immediate distribution to oceanographic and meteorological centers around the world.

The TAO array was developed under auspices of the recently completed 10-yr (1965-94) international Tropical Ocean-Global Atmosphere (TOGA) Program. A major objective of TOGA was to develop an ocean observing system to support studies of large-scale ocean-atmosphere interactions on seasonal to interannual timescales. The need for such an observing system was dramatized in the early planning stages for TOGA by the occurrence of the 1982-83 ENSO, the strongest of the century, which was neither predicted nor even detected until nearly at its peak. TAO is now one of the cornerstones of this observing system, which also includes drifting buoy arrays, a

Corresponding author address: Michael J. McPhaden, NOAA/ Pacific Marine Environmental Laboratory, 7600 Sand Point Way NE, Seattle, WA 98115.

In final form 29 March 1995.

(C)1995 American Meteorological Society volunteer observing ship expendable bathythermograph network, island and coastal tide gauges, an island wind profiler network, and remotely sensed measurements from both operational and research satellites.

ENSO events occur periodically at intervals of roughly 2 to $7 \mathrm{yr}$ and typically last for about 12 to 18 months. During ENSO, the Pacific trade winds weaken, causing eastward migration of the western Pacific warm pool into the central Pacific, and reduced equatorial upwelling in the eastern Pacific. Anomalously warm sea surface temperatures appear from the coast of South America to west of the international date line, which leads to further weakening of the trade winds. The ocean-atmosphere system therefore becomes locked in a positive feedback loop that is ultimately broken when planetary-scale oceanic wave processes excited by the collapse of the trade winds readjust the upper-ocean thermal structure and induce surface cooling.

In the atmosphere, the pattern of deep convection and precipitation shifts eastward with the warmest sea surface temperatures during ENSO, leading to drought conditions in northern Australia, Indonesia, and the Philippines; and excessive rains in the island states of the central tropical Pacific and along the west coast of South America. Anomalous latent heating of the atmosphere associated with this eastward shift in convection alters the general circulation of the atmosphere, extending the influence of ENSO not only to other tropical regions (drought conditions in northeast Brazil, southern Africa, and a weakened Indian monsoon), but also to higher latitudes. For example, during ENSO events, most of Canada and the northwestern United States tend to experience mild winters, and the states bordering the Gulf of Mexico tend to be cooler and wetter than normal. California has experienced a disproportionate share of its episodes of heavy rainfall during ENSO winters such as 1982-83, 1991-92, and 1994-95, but other ENSO winters, such as 1976-77, have been among the driest on record. ENSO also 


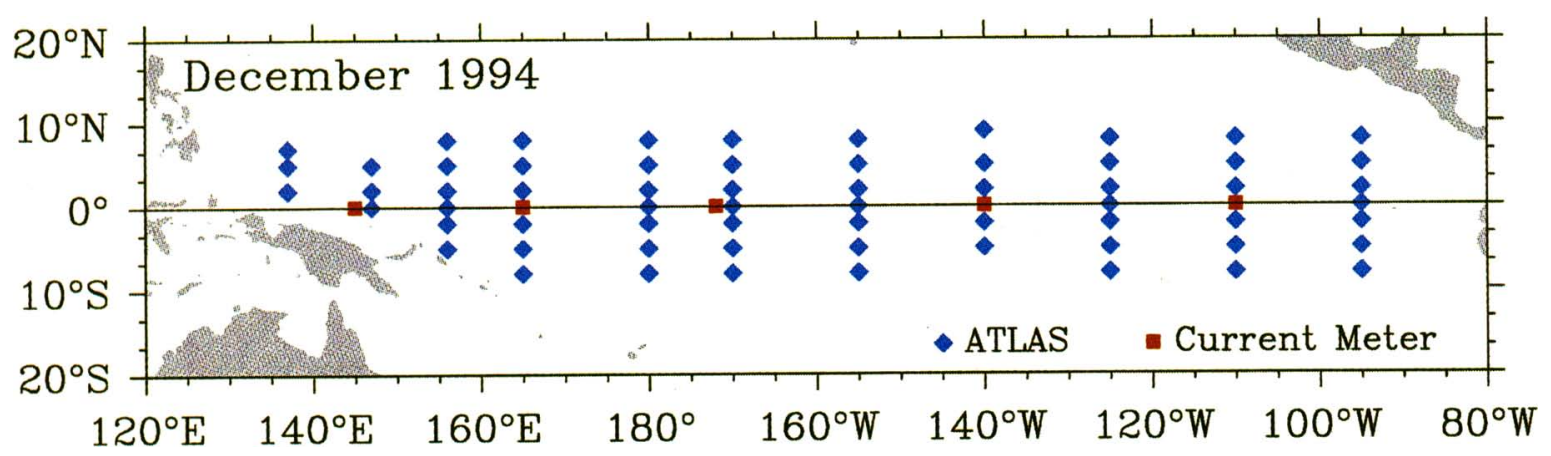

Fig. 1. Tropical Atmosphere Ocean array.

disrupts the marine ecology of both the tropical Pacific and the Pacific coast regions of the Americas, affecting the mortality and distribution of commercially valuable fish stocks and socioeconomic consequences that are felt worldwide.

The history of moored measurements for climate studies in the equatorial Pacific dates back to the late 1970s, when David Halpern of NOAA's Pacific Marine Environmental Laboratory (PMEL) was the first to successfully deploy and maintain surface moorings in the strongly sheared flows of the equatorial current system. Based in part on the success of this early pioneering effort, the late Stan Hayes of PMEL conceived of a pan-Pacific moored array that would telemeter in real time the essential variables needed to improve the detection, understanding, and prediction of ENSO. Hayes named this array the TOGA Tropical Atmosphere Ocean array. Key to the successful implementation of the TAO array was the development of the low-cost Autonomous Temperature Line Acquisition System (ATLAS) mooring, which measures and telemeters in real time surface winds, sea surface temperature, and subsurface temperatures to depths of $500 \mathrm{~m}$. Ocean currents are involved in the zonal redistribution of upper-ocean heat content on seasonal to interannual timescales, so a small number of moorings along the equator measure upper ocean velocity. Surface air temperature and relative humidity are measured at all mooring sites; additional sensors, such as rain gauges, salinometers, short-wave radiometers, and bio-optical sensors, have been added for specialized studies.

One measure of the TAO array's success is the growing number of publications (almost 200 in the past three years) that make use of the mooring data. The topics covered in these publications are diverse, ranging from detection of new phenomena (such as $60-$ 90-day oceanic equatorial Kelvin waves) to description of recent ENSO events, tests of ENSO theories, studies of atmospheric boundary layer dynamics, veri- fication of ocean and atmosphere models used for climate research, data assimilation into climate models, satellite validation (of sea level, sea surface temperature, surface wind speed and velocity, and rainfall), etc. Moreover, the TAO array provides a broad geographic perspective and long time history to aid in the interpretation of measurements from shorter duration, regional-scale observational studies. Examples of recent process-oriented field programs embedded in the TAO array include the Tropical Instability Wave Experiment to study the life cycle and energy sources for tropical instability waves in the eastern Pacific (1990-91), the TOGA Coupled Ocean-Atmosphere Response program to study ocean-atmosphere interactions in the western Pacific warm pool (1992-94), the Joint Global Ocean Flux Studies Equatorial Pacific Experiment to study biogeochemical cycling in the upper ocean (1992), and the Central Equatorial Pacific Experiment to study cloud-radiative feedbacks (1993).

In addition, TAO array data have improved the quality of several important operational climate analysis and prediction products. TAO array data available on the Global Telecommunications System are incorporated into surface wind analyses at weather prediction centers around the world, such as at NOAA's National Centers for Environmental Prediction (NCEP) in Washington, D.C.; the Fleet Numerical Oceanography Center in Monterey, California; the European Centre for Medium-Range Weather Forecasts in the United Kingdom; Météo-France in Toulouse, France; etc. Also, operational short-term climate predictions at NCEP, based on state-of-theart coupled ocean-atmosphere models, are dependent on assimilation of TAO array subsurface temperature data for accurate ocean initialization. Finally, TAO array sea surface temperature data are incorporated into the operational satellite/in situ blended analyses produced at NCEP, and the TAO array is a major data source for tropical Pacific wind analyses performed at The Florida State University. 
ATLAS moorings and most current meter mooring are assembled at PMEL; all sensors are calibrated prior to deployment and after recovery. ATLAS moorings have a one-year design lifetime and current meter moorings have 6-month to 1-year design lifetimes, so servicing the array is an ongoing effort. Accumulated over the 10 years of the TOGA program between 1985 and 1994, more than 400 TAO moorings have been deployed on 83 research cruises involving 17 ships from six different countries, requiring a total of 5.7 years of ship time. Currently, nearly one year of dedicated ship time per calendar year is required to maintain the fully implemented array of 69 moorings. Data return from the array is greater than $80 \%$, with a significant percentage of the loss due to vandalism by fishing fleets in the far eastern and western Pacific.

Scientific use of the moored measurements has been encouraged by the development at PMEL of sophisticated data management and dissemination capabilities. These include the TAO workstation software, which is a user friendly, Unix-based interactive data display, analysis, and distribution system; the creation of an Internet anonymous file transfer protocol database at PMEL; and distribution of TAO data and analyses through the World Wide Web, using interfaces such as MOSAIC (http://www/pmel.noaa.gov/toga-tao/real-time.html). Yearly submissions of TAO data are made to the National Oceanographic Data Center in Washington, D.C.; the National Climate Data Center in Asheville, North Carolina; and the TOGA Subsurface Data Center in Brest, France. TAO array data are also available on the TOGA compact disc produced by the Jet Propulsion Laboratory in Pasadena, California.

The TAO array was finally completed just as the TOGA program, which sponsored it, came to an end. However, new national and international research programs have been formulated to build on the suc- cesses of TOGA-namely, the U.S. Global Ocean Atmosphere Land System (GOALS) program, and the World Climate Research Program's study of Climate Variability and Predictability (CLIVAR). These programs, scheduled for the 15-year period 1995-2010, will continue and expand upon seasonal to interannual climate research initiated during TOGA. Maintenance of the TAO array, as well as other components of the TOGA observing system, is key to the success of these new climate research programs.

Long-term support of critical climate measurements has motivated planning for the Global Climate Observing System (GCOS) as well as the climate module of the Global Ocean Observing System (GOOS). Based on the success of TOGA, the observational requirements of CLIVAR/GOALS, and the potential for improving the skill of seasonal to interannual climate forecasts, the TAO array has been identified as a centerpiece of the initial U.S. contribution to the climate module of GOOS and to the ocean component of GCOS. Moreover, possible expansions of the TAO array to other tropical ocean basins and/or to higher latitudes in the Pacific can be envisioned in response to evolving scientific objectives in CLIVAR/GOALS. To meet the observational challenges of the future, a new generation of low-cost mooring is being developed with increased design lifetime and measurement capabilities. In addition, array design assessments are under way to optimize present and future sampling strategies for climate studies.

The TAO project is a multinational effort involving the participation of the United States, Japan, Korea, Taiwan, and France. Funding in the United States has been provided primarily by NOAA's Office of Global Programs and by the Office of Oceanic and Atmospheric Research. The TAO Project Office, under the direction of Michael J. McPhaden, is located at NOAA's Pacific Marine Environmental Laboratory in Seattle, Washington. 


\title{
correspondence
}

\section{A Plan for a Shared Library for Aircraft Processing Software}

\author{
Bruno Piguet, ${ }^{*}$ Jean-Louis Brenguier, ${ }^{*}$ and Alfred R. Rodi ${ }^{+}$
}

\section{Background}

Research aircraft play an important role in the in situ measurement of atmospheric phenomena. The accuracy of these measurements is conditioned by both the instruments installed on the aircraft and the procedures applied for correcting the atmospheric perturbations due to the aircraft. Instrumental studies are numerous and extensively published. There is also a large body of software for processing data from research aircraft, but there is little or no structured effort to share this software.

The authors of aircraft data software form a diverse group of programmers, engineers, and scientists. Some work in aircraft facilities, but many are scientists and staff in laboratories and departments independent of aircraft operations. Thus, communication among these individuals is often intermittent.

After informal discussions among several individuals over a period of time, a group of people interested in the problem decided to gather at a workshop to investigate the establishment of a shared library of aircraft data processing software (SLAPS). The objective of the shared library is to facilitate the sharing of processing methods and routines in order to improve data processing and the identification of procedures for data intercomparison. This workshop took place from 14 to 18 June 1993 at the Centre National de Recherche Meteorologie (CNRM) at Météo-France in Toulouse, France. There were 24 participants from Canada, France, Germany, Great Britain, and the United States. The presentations at the workshop were grouped into three sections: 1) processing meth-

\footnotetext{
*Météo-France, CNRM/GMEI/MMA, Toulouse, France.

+Department of Atmospheric Science, University of Wyoming, Laramie, Wyoming.

Corresponding author address: Bruno Piguet, Météo-France, CNRM/GMEI/MMA, 42, Av. Coriolis, 31057 Toulouse, Cedex, France. In final form 7 November 1994.

(C)1995 American Meteorological Society
}

ods, algorithms, and systems; 2) data management; and 3) code management.

The purpose of this correspondence is to record the results of the workshop, communicate to the general atmospheric sciences community the history and objectives of the working group, and solicit broader participation and contributions to the shared library.

\section{Definition of aircraft data processing}

Processing of data is a multifaceted activity if one considers all the steps necessary to process and archive measurements taken on airborne platforms. In the working group's current effort, consideration was given mainly to the derivation of physical parameters from aircraft measurements. While many of these steps are common with processing data from other observing systems in the atmospheric sciences, such as rawinsondes and mesonet stations, there are some aspects of the problem that are mainly the consideration of fast-moving platforms such as aircraft. A simple example is the computation of static air temperature from the measured air temperature, which includes the effects of dynamic heating. Another example is wind measurement by the drift method, where rapidly changing ground speed and airspeed vectors are substracted to derive the three-dimensional wind vector. The group decided to exclude from its deliberations the consideration of standardized formats for aircraft data, but this decision may be reversed at a later time.

\section{Problems: Errors and discrepancies among aircraft datasets}

There are two principal aspects of the problem that are being addressed here. The first relates to traceability of processing methods and the second to reliability. 


\section{a. Traceability of processing methods}

When one uses aircraft data for scientific analyses, one states the source of the data (the aircraft facility) but rarely the methods used in the processing. For example, one uses JW (Johnson-William) liquid water content from a particular aircraft, but the methods for processing are not explicitly stated. To investigate the steps taken in the processing (true airspeed correction, zero drift, etc., to continue with the JW example), one needs to contact the facility that processed the data and speak with the expert in that area. Technical documentation is often but not always available. When intercomparisons are done between aircraft from different facilities there are often discrepancies. Interpretation is also difficult because the methods used are not the same. For all but "insiders" these considerations are often quite confusing, and the history of changes is poorly documented.

\section{b. Reliability}

Multiple aircraft datasets have also shown discrepancies due to "errors" in processing, both minor (such as choice of physical constants) and sometimes major (coding errors, etc.). Therefore, it is difficult to diagnose the source of differences among aircraft. Similar instruments are used on most research aircraft so that expertise is easily shared. However, processing codes are generally quite different and improvements are difficult to disseminate.

\section{Advantages of a shared library}

The advantages of a shared library, then, are further presented as the following.

1) Reliability: A library of well-tested and documented subroutines could minimize the errors caused by each group writing separate code. Also, different methods of calculation could be intercompared.

2) Efficiency: Groups could share code and thereby minimize effort.

3) Facilitatation of communication among groups: New developments could be communicated to interested individuals.

4) Consistency

(i) Standardization: While several valid solutions to derivations may be available, implementations may vary. A shared library could minimize the uncertainties in the methods.

(ii) Traceability: Users of data could reference subroutines from the shared library by name, facilitating interpretation of the results.

5) Dissemination of well-tested and dependable techniques.
6) History of developments: Well-documented software, including all the necessary references to the source of the algorithms used, often preserves the evolution of a particular instrument or system with more detail than what is ever included in a journal article.

7) For the authors, the benefit would be the feedback and improvements obtained from the testing of code by others.

\section{Recommendations from the workshop}

The consensus of the workshop participants was that a shared library would well address the objectives listed above.

There is no suggestion that any routines included in the library will necessarily represent the "best" method of performing any particular data processing task. Hence, there is no attempt to try and enforce standardization but rather just to enable other users to make use of alternative algorithms (and their included expertise) for particular purposes.

For the implementation of this library, it was generally agreed that the usefulness of the library and individual submissions would be proportional to the degree of documentation and portability. The following recommendations were made:

1) The library be open to contributions without formal criteria for acceptance.

2) Documentation of submissions is recommended and should contain the following material: name of author (or contributor), revision information, technical notes, literature references for the method, and, in the code itself, a header block. The header block should contain information about the input and output variables, global or common variables, etc.

3) Means of obtaining the software code itself would vary from submission to submission. For authors who wish to control distribution, the library could contain the documentation, and the code would be available directly from the author. Other authors might wish to submit the code to be available anonymously via FTP transmission or e-mail request. In all cases, the authors would determine the rules for distribution of their respective code.

4) The library reside and be administered initially at CNRM.

5) A second workshop be held in about a year to further facilitate communication within the group.

As a first step, the initial entries in the library will be a basic set of routines. An effort will be made to 
1) enlarge the group of authors,

2) intercompare submissions, and

3) facilitate communication among the groups to stimulate new developments.

\section{Conclusions}

We feel that this is a good time to initiate a shared library for aircraft data processing because we know that several groups are at present rewriting their processors and putting their subroutines into libraries that could be readily shared. The benefits of this effort, we feel, would be mainly the reliability and traceability of aircraft measurements, the facilitation of communication among the various groups and individuals, and economy of effort in the development of high quality and tested data processing methods and software.

\section{Further information}

You can contact the SLAPS group via e-mail address: SLAPS-talk@xdata.cnrm.meteo.fr. To obtain information about the shared library or to add your e-mail address to the SLAPS-talk e-mail list, contact J. L. Brenguier at CNRM (Tel: 33.61.07.93.21; Fax: 33.61.07.96.27; e-mail: jlb@meteo.fr) or B. Piguet (Tel: 33.61.07.96.59; e-mail: Bruno.PIGUET@ meteo.fr). Also, anonymous FTP to the SLAPS computer can be done via an Internet address: mma1.cnrm.meteo.fr 7500 (it is important to mention the "7500" port number), or you can use the numeric form 139.127.159.1 7500 , but it may change in the future.

Acknowledgments. We wish to thank Philip R. A. Brown and lan MacPherson for their comments and help with editing this note.

\section{The Representation of Cumulus Convection in Numerical Models}

\section{Meteorological Monograph No. 46}

Cumulus convection is perhaps the most complex and perplexing subgrid-scale process that must be represented in numerical models of the atmosphere. It has been recognized that the water vapor content of large parts of the atmosphere is strongly controlled by cloud microphysical processes, yet scant attention has been paid to this problem in formulating most existing convection schemes. This monograph is the fruit of the labors of many of the leading specialists in convection and convective parameterization to discuss this and other issues. Its topics include: an overview of the problem; a review of "classical" convection schemes in widespread use; the special problems associated with the representation of convection in mesoscale and climate models; the parameterization of slantwise convection; and some recent efforts to use explicit numerical simulations of ensembles of convective clouds to test cumulus representations.

(C) 1994 American Meteorological Society. Hardbound, B\&W, 246 pp., $\$ 65$ list $\backslash \$ 45$ members (includes shipping and handling). Please send prepaid orders to: Order Department, American Meteorological Society, 45 Beacon St., Boston, MA 02108-3693.

\section{American Meteorological Society}

